\title{
Label-Free Mass Spectrometry
}

National Cancer Institute

\section{Source}

National Cancer Institute. Label-Free Mass Spectrometry. NCI Thesaurus. Code

C161800.

Mass spectrometry performed with samples that have not been subjected to isotopic labeling. 